\title{
ANALISIS TINGKAT KERUSAKAN BANGUNAN GEDUNG SEKOLAH MENENGAH PERTAMA (SMP) DI MALUKU
}

\author{
Meidy Kempa \\ meidykempa@yahoo.com \\ Teknik Sipil, Fakultas Teknik Universitas Pattimura
}

\begin{abstract}
ABSTRAK
Gedung sekolah sebagai komponen utama dalam pelaksanaan proses belajar mengajar merupakan salah satu faktor yang berpengaruh besar dalam penentuan mutu suatu lembaga pendidikan, termasuk Sekolah Menengah Pertama (SMP), sehingga membutuhkan pemeliharaan secara berkala. Untuk meningkatkan kualitas pendidikan di Maluku, pemerintah daerah perlu melakukan upaya salah satunya dengan melakukan identifikasi kondisi fisik terhadap bangunan gedung sekolah. Penelitian ini bertujuan untuk melakukan identifikasi tentang kondisi bangunan dan tingkat kerusakan bangunan gedung SMP di provinsi Maluku, serta menentukan ranking (persentase) kerusakan pada elemen bangunan bangunan gedung SMP di provinsi Maluku. Hasil penelitian menunjukan bahwa dari 100 SMP yang tersebar di 10 kabupaten di provinsi Maluku, didapat bahwa pada ruang kelas, 17.92\% dalam kondisi baik, 69.42\% rusak ringan, 7.14\% rusak sedang, 3.51\% rusak berat, 2.01\% rusak total. Sedangkan pada ruang penunjang lainnya, 34.67\% dalam kondisi baik, $47.31 \%$ rusak ringan, $7.38 \%$ rusak sedang, $5.63 \%$ rusak berat, dan $5.01 \%$ rusak total.
\end{abstract}

Kata Kunci : Kondisi bangunan, tingkat kerusakan, gedung sekolah menengah pertama (SMP)

\section{PENDAHULUAN}

Gedung sekolah sebagai komponen utama dalam pelaksanaan proses belajar mengajar merupakan salah satu faktor yang berpengaruh besar dalam penentuan mutu suatu lembaga pendidikan, dalam hal ini pada tingkat Sekolah Dasar (SD), Sekolah Menengah Pertama (SMP), sampai Sekolah Menengah Atas (SMA). Selain itu, ketersediaan sarana dan prasarana pendidikan juga termasuk faktor yang mendukung hal tersebut diatas. Sebagai komponen utama dalam pelaksanaan proses belajar mengajar inilah, maka gedung sekolah membutuhkan pemeliharaan secara berkala. Menurut Iriana et al (2012), Kurangnya perhatian atau tidak sesuainya kegiatan pemeliharaan bangunan sekolah yang dilakukan, akan menyebabkan suatu kondisi atau dampak negatif, yaitu menurunnya tingkat produktivitas kegiatan-kegiatan yang dilaksanakan oleh pemilik atau pengguna bangunan sebagai akibat dari kurang terpeliharanya kondisi bangunan. Hal inilah yang perlu segera diperhatikan oleh pemerintah pusat maupun daerah karena sangat berpengaruh besar dalam penentuan mutu pendidikan suatu daerah.

Menurut Ikhtisar Data Pendidikan Kementerian Pendidikan dan Kebudayaan (2017), Maluku masuk dalam kategori 5 provinsi yang memiliki hal kualitas pendidikan terrendah di Indonesia. Oleh karena itu, pemerintah daerah perlu berupaya untuk meningkatkan mutu pendidikan agar tidak tertinggal dengan provinsi atau daerah lainnya di Indonesia. Salah satu upaya yang bisa dilakukan adalah dengan melakukan identifikasi kondisi fisik sarana dan prasarana sekolah, termasuk di dalamnya melakukan identifikasi terhadap kondisi bangunan atau gedung sekolah.

Berdasarkan realita yang dijelaskan diatas, maka dilakukan penelitian pada gedung Sekolah Menengah Pertama (SMP) di Provinsi Maluku, untuk mengidentifikasi tingkat kerusakan bangunan gedung guna menunjang pemerintah daerah khususnya dalam hal peningkatan mutu pendidikan di Maluku.

Penelitian ini bertujuan untuk :

1. Mengidentifikasi kondisi bangunan dan tingkat kerusakan bangunan gedung Sekolah Menengah Pertama (SMP) di Provinsi Maluku

2. Membuat ranking (persentase) kerusakan pada bangunan gedung Sekolah Menengah Pertama (SMP) di Provinsi Maluku

\section{KAJIAN TEORI DAN METODE 2.1. TINGKAT KERUSAKAN BANGUNAN \\ 2.1.1 Definisi \& Kategori Tingkat Kerusakan Bangunan}

Menurut Dardiri (2012), kerusakan bangunan merupakan proses melemahnya kekuatan dan ketahanan konstruksi dan material bangunan meneriman beban-beban dari luar atau beban berat 
sendiri sehingga melebihi kapasitasnya. Kerusakan bangunan menurut Permen PU No.24 Tahun 2008 adalah tidak berfungsinya bangunan atau komponen bangunan akibat penyusutan/berakhirnya umur bangunan, atau akibat ulah manusia, atau perilaku alam seperti beban fungsi yang berlebih, kebakaran. gempa bumi, atau sebab lain yang sejenis. Intensitas kerusakan bangunan dapat digolongkan atas tiga tingkat kerusakan, yaitu :

1. Kerusakan Ringan

Kerusakan ringan adalah kerusakan terutama pada komponen non struktural, seperti penutup atap, langit-langit, penutup lantai, dan dinding pengisi.

2. Kerusakan Sedang

Kerusakan sedang adalah kerusakan pada sebagian komponen non struktural dan atau komponen struktural seperti struktur atap, lantai, dan lain-lain.

3. Kerusakan Berat

Kerusakan berat adalah kerusakan pada sebagian besar komponen bangunan, baik struktural maupun non struktural yang apabila setelah diperbaiki masih dapat berfungsi dengan baik sebagaimana mestinya.

Sedangkan menurut Pedoman Teknis Bangunan Tahan Gempa yang dikeluarkan oleh Direktorat Jenderal Cipta Karya (2006), membagi tingkat kerusakan bangunan gedung atas 5 kategori, antara lain :

1. Kerusakan Ringan Non Struktur

Suatu bangunan dikategorikan mengalami kerusakan non struktur apabila terjadi hal-hal sebagai berikut :

a. Retak halus (lebar celah lebih kecil dari $0.075 \mathrm{~cm}$ ) pada plesteran

b. Serpihan plesteran berjatuhan

c. Mencakup luas yang terbatas

2. Kerusakan Ringan Struktur

Suatu bangunan dikategorikan mengalami kerusakan struktur tingkat ringan apabila terjadi hal-hal sebagai berikut :

a. Retak kecil (lebar celah antara $0.075 \mathrm{~cm}$ hingga $0.6 \mathrm{~cm}$ ) pada dinding

b. Plester berjatuhan

c. Mencakup luas yang besar

d. Kerusakan bagian-bagian non struktur seperti cerobong, listplank, dsb

e. Kemampuan struktur untuk memikul beban tidak banyak berkurang

f. Laik fungsi/huni

3. Kerusakan Struktur Tingkat Sedang
Suatu bangunan dapat dikategorikan mengalami kerusakan struktur tingkat sedang apabila terjadi hal-hal sebagai berikut :

a. Retak besar (lebar celah lebih dari $0.6 \mathrm{~cm}$ ) pada dinding

b. Retak menyebar luas di banyak tempat, seperti pada dinding pemikul beban, kolom, c erobong miring, dan runtuh

c. Kemampuan struktur untuk memikul beban sudah berkurang sebagian

d. Laik fungsi/huni

4. Kerusakan Struktur Tingkat Berat

Suatu bangunan dikategorikan mengalami kerusakan struktur tingkat berat apabila terjadi hal-hal sebagai berikut :

a. Dinding pemikul beban terbelah dan runtuh

b. Bangunan terpisah akibat kegagalan unsurunsur pengikat

c. Kira-kira $50 \%$ elemen utama mengalami kerusakan

d. Tidak laik fungsi/huni

5. Kerusakan Total

Suatu bangunan dikategorikan sebagai rusak total/roboh apabila terjadi hal-hal sebagai berikut :

a. Bangunan roboh seluruhnya ( $>65 \%$ )

b. Sebagian komponen utama struktur rusak

c. Tidak laik fungsi/huni

\subsubsection{Identifikasi Komponen Penyusun Bangunan}

Menurut Direktorat Pembinaan Sekolah Dasar Kemendikbud RI dalam Parmo (2016), menyatakan bahwa bangunan gedung terdiri atas komponen-komponen penyusunnya. Komponenkomponen tersebut adalah komponen struktur, arsitektural, dan utilitas yang kemudian diuraikan lagi menjadi elemen dan sub elemen seperti pada Tabel 2.1 (a), Tabel 2.1 (b), dan Tabel 2.1 (c)

Tabel 2.1 (a) Komponen struktur penyusun bangunan gedung sekolah

\begin{tabular}{|l|l|l|l|}
\hline Elemen & $\begin{array}{l}\text { Struktur } \\
\text { Atap }\end{array}$ & Struktur Atas & $\begin{array}{l}\text { Struktur } \\
\text { Bawah }\end{array}$ \\
\hline Elemen & $>$ Rangka & $>$ Kolom : & $>$ Sloof \\
& Atap : & - Kolom struktur & \\
& - Kuda-kuda & - Kolom praktis & \\
& - Murplat & & \\
& - Gording & & \\
& - Nok & & \\
& - Ikatan & & \\
& Angin & & \\
& - Usuk \& & & \\
\cline { 2 - 4 } & reng & $>$ Balok: & $>$ Pondasi : \\
& & - Balok induk & - Footplat \\
& & - Balok anak & - Batu kali \\
\hline
\end{tabular}




\begin{tabular}{|l|l|l|l|}
\hline & - Balok ring & - Sumuran \\
& & - Balok latai & \\
& - Balok konsol & \\
\cline { 2 - 4 } & & $>$ Pelat : & \\
& - Pelat atap & \\
& - Pelat lantai & \\
\hline & - Pelat leufel & \\
\hline
\end{tabular}

Tabel 2.1 (b), Komponen arsitektural penyusun bangunan sekolah

\begin{tabular}{|c|c|}
\hline \\
\hline Elemen & Sub Elemen \\
\hline Penutup Atap & $\begin{array}{l}>\text { Genteng/Asbes gelombang/seng gelombang } \\
\text { Papan ruiter, listplank, papan talang \& } \\
\text { konsol } \\
>\quad \text { Bubungan }\end{array}$ \\
\hline Langit-langit & $\begin{array}{ll}> & \text { Rangka plafond } \\
& \text { Penutup plafond } \\
& \text { List plafond } \\
& \text { Cat plafond }\end{array}$ \\
\hline Dinding & \begin{tabular}{ll} 
& \multicolumn{2}{l}{ Dinding bata : } \\
- & Pasangan bata \\
- & Plesteran \\
- & Acian \\
- & Cat dinding \\
$>$ & Dinding partisi : \\
- & Rangka partisi \\
- & Penutup partisi \\
- & Cat partisi \\
\end{tabular} \\
\hline $\begin{array}{ll}\text { Pintu } & \text { dan } \\
\text { Jendela } & \end{array}$ & $\begin{array}{ll}> & \text { Pintu : } \\
- & \text { Kusen pintu } \\
- & \text { Daun pintu } \\
- & \text { Engsel } \\
\text { - } & \text { Handle } \\
\text { - } & \text { Kunci } \\
\text { - } & \text { Cat/politer } \\
\text { Jendela : } \\
\text { - } & \text { Kusen jendela } \\
\text { - } & \text { Daun jendela } \\
\text { - } & \text { Kaca/krepyak } \\
\text { - } & \text { Engsel } \\
\text { - } & \text { Hak angin } \\
\text { - } & \text { Grendel } \\
- & \text { Cat/politur } \\
\end{array}$ \\
\hline $\begin{array}{ll}\text { Lantai } & \text { dan } \\
\text { Keramik } & \end{array}$ & $\begin{array}{ll}> & \text { Rabat beton/patlah bata } \\
> & \text { Keramik lantai } \\
> & \text { Keramik dinding }\end{array}$ \\
\hline
\end{tabular}

Tabel 2.1 (c), Komponen utilitas penyusun bangunan sekolah

\begin{tabular}{|c|c|c|c|}
\hline Elemen & Sistem Plumbing & M/E & $\begin{array}{c}\text { Elektrikal } \\
\text { Bangunan }\end{array}$ \\
\hline Sub & $>$ Saluran Buangan : & $>$ Pompa & $>$ Instalasi \\
Elemen & - Instalasi air kotor & air & listrik \\
& - Instalasi air bersih & & $>$ Saklar \\
& - Instalasi air hujan & & $>$ Stop \\
& - Bak control & & kontak \\
& $>$ Distribusi air bersih: & & $>$ Lampu \\
& - Instalasi air bersih ke & & $>$ Armate \\
& KM/WC, meja cuci, & & ur \\
& wastafel, tandon air & & $>$ Fitting \\
& $>$ Sanitair : & & $>$ Sekring/ \\
& - Wastafel & & MCB \\
& - Kloset & & $>$ Penyam \\
& - Bak air & & bungan \\
& - Septictank & & daya \\
\hline
\end{tabular}

\subsubsection{Menentukan Kriteria \& Perhitungan Tingkat Kerusakan Bangunan}

Cara menentukan kriteria tingkat kerusakan bangunan adalah dengan menggunakan metode pembobotan. Metode pembobotan dan prosedur perhitungan tingkat kerusakan mengacu pada Panduan Verifikasi Bantuan Revitalisasi Sekolah Dasar oleh Direktorat Pembinaan Sekolah Dasar Kemendikbud RI 2015. Pembobotan ini diperoleh dengan cara mengisi isian instrument oleh pihak sekolah atau surveyor ahli. Kemudian hasil survey tersebut dianalisis oleh tenaga ahli yang berkompeten untuk memperoleh tingkat kerusakan untuk tiap elemen bangunan atau ruangan. Untuk perhitungan tingkat kerusakan setiap elemen/komponen bangunan, dinyatakan dalam satuan persentase tingkat kerusakan, dimana cara perhitungannya mengacu pada Panduan Verifikasi Bantuan Revitalisasi Sekolah Dasar oleh Direktorat Pembinaan Sekolah Dasar Kemendikbud RI 2015, seperti pada Tabel 2.2 dibawah ini.

Tabel 2.2. Cara perhitungan persentase tingkat kerusakan bangunan sekolah (Kemendikbud, 2015)

\begin{tabular}{|c|c|c|}
\hline No & $\begin{array}{l}\text { Komponen } \\
\text { Bangunan }\end{array}$ & $\begin{array}{l}\text { Persentase tingkat } \\
\text { kerusakan }\end{array}$ \\
\hline \multirow[t]{4}{*}{1} & \multirow[t]{4}{*}{ Penutup atap } & Luas $A=(c+d) \times(e+f) \times 1,2$ \\
\hline & & Luas $B=(a+b) \times(e+f) \times 1,2$ \\
\hline & & $\begin{array}{l}\text { Luas } C=\text { luasan penutup } \\
\text { yang rusak }\end{array}$ \\
\hline & & $\begin{array}{l}\text { Tingkat kerusakan penutup } \\
\text { atap }=\text { Luas } C / \text { (Luas } A+ \\
\text { Luas B) } \times 100 \%\end{array}$ \\
\hline \multirow[t]{5}{*}{2} & \multirow[t]{5}{*}{ Rangka atap } & Luas $A=(c+d) \times(e+f) \times 1,2$ \\
\hline & & Luas $B=(a+b) \times(e+f) \times 1,2$ \\
\hline & & $\begin{array}{l}\text { Luas } C=\text { luasan rangka atap } \\
\text { yang rusak }\end{array}$ \\
\hline & & $\begin{array}{l}\text { Tingkat kerusakan rangka } \\
\text { atap }=\text { Luas } \mathrm{C} /(\text { Luas } \mathrm{A}+ \\
\text { Luas } \mathrm{B}) \times 100 \%\end{array}$ \\
\hline & & $\begin{array}{l}\text { Tingkat kerusakan kuda- } \\
\text { kuda }=\text { Jumlah kuda-kuda } \\
\text { yang rusak/Jumlah seluruh } \\
\text { kuda-kuda di ruang tersebut } \\
\times 100 \%\end{array}$ \\
\hline \multirow[t]{3}{*}{3} & \multirow[t]{3}{*}{ Rangka plafon } & $\begin{array}{l}\text { Luas rangka plafond yang } \\
\text { rusak }=\text { Luas }(A+B)\end{array}$ \\
\hline & & $\begin{array}{l}\text { Luas total rangka plafond }= \\
(a+b) \times c\end{array}$ \\
\hline & & $\begin{array}{l}\text { Persentase tingkat } \\
\text { kerusakan = Luas } \\
(A+B) /((a+b) \times c) \times 100 \%\end{array}$ \\
\hline \multirow[t]{3}{*}{4} & \multirow[t]{3}{*}{ Penutup plaf } & $\begin{array}{l}\text { Luas penutup plafond yang } \\
\text { rusak }=\text { Luas }(A+B)\end{array}$ \\
\hline & & $\begin{array}{l}\text { Luas total penutup plafond }= \\
(a+b) \times c\end{array}$ \\
\hline & & $\begin{array}{l}\text { Persentase tingkat } \\
\text { kerusakan }=\text { Luas } \\
(A+B) /((a+b) \times c) \times 100 \%\end{array}$ \\
\hline
\end{tabular}




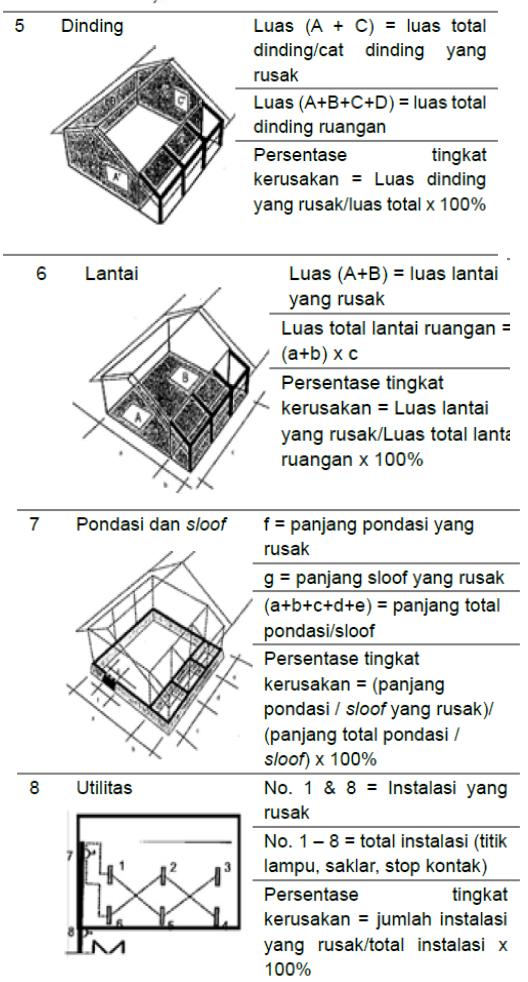

Dengan menggunakan perhitungan sesuai Tabel 2.2, maka persentase bobot tingkat kerusakan untuk setiap elemen/komponen bangunan dapat dihitung. Setelah itu, tingkat kerusakan kumulatif untuk tiap ruangan dilakukan pembobotan dengan menggunakan tools pembobotan seperti pada Tabel 2.3 berikut ini.

Tabel 2.3. Komponen standar penilaian tingkat kerusakan bangunan gedung sekolah (Kemendikbud, 2015)

\begin{tabular}{|c|c|c|c|c|c|}
\hline \multirow[b]{2}{*}{ No } & \multirow[b]{2}{*}{$\begin{array}{c}\text { Komponen \& Sub } \\
\text { Komponen Bangunan }\end{array}$} & \multicolumn{2}{|c|}{$\begin{array}{ll}\text { Bobot (\%) } \\
\end{array}$} & \multicolumn{2}{|c|}{ Tingkat Kerusakan (\%) } \\
\hline & & $\begin{array}{c}\text { Terhadap seluruh } \\
\text { bangunan }\end{array}$ & \begin{tabular}{|l|} 
Kerusakan \\
Maksimum
\end{tabular} & Bobot & Nilai \\
\hline (1) & (2) & (3) & (4) & (5) & $(6)=(3) \times(5)$ \\
\hline \multirow{4}{*}{1} & Atap & & & & \\
\hline & a. Penutup Atap & 10.56 & 100 & & \\
\hline & b. Rangka Atap & 11.62 & 100 & & \\
\hline & c. Listplank \& Talang & 2.06 & 100 & & \\
\hline \multirow{4}{*}{2} & Plafond & & & & \\
\hline & \begin{tabular}{|l} 
a. Rangka Plafond \\
\end{tabular} & 4.67 & 100 & & \\
\hline & b. Penutup \& List & 5.06 & 100 & & \\
\hline & c. Cat plafond & 1.41 & 100 & & \\
\hline & Dinding & & & & \\
\hline & a. Kolom \& ringbalk & 9.66 & 100 & & \\
\hline & $\begin{array}{l}\text { b. Pas. Bata \& Dinding } \\
\text { Pengisi }\end{array}$ & 13.68 & 100 & & \\
\hline & \begin{tabular}{|l|l} 
c. Cat dinding \\
\end{tabular} & 1.65 & 100 & & \\
\hline \multirow{4}{*}{4} & Kusen, Pintu \& Jendela & & & & \\
\hline & \begin{tabular}{|l|} 
a. Kusen \\
\end{tabular} & 2.70 & 100 & & \\
\hline & b. Daun Pintu & 2.47 & 100 & & \\
\hline & \begin{tabular}{|l} 
c. Daun Jendela \\
Daun Jendel
\end{tabular} & 5.15 & 100 & & \\
\hline \multirow{3}{*}{5} & Lantai & & & & \\
\hline & a. Struktur bawah & 2.89 & 100 & & \\
\hline & b. Penutup Lantai & 8.96 & 100 & & \\
\hline \multirow{2}{*}{6} & \begin{tabular}{|l|} 
Pondasi \\
Pondasi
\end{tabular} & $\begin{array}{ll}11.15 \\
\end{array}$ & 100 & & \\
\hline & \begin{tabular}{|l|} 
a. Pondasi \\
b. Sloof
\end{tabular} & 3.30 & 100 & & \\
\hline \multirow[t]{3}{*}{7} & Utilitas & & & & \\
\hline & a. Listrik & 1.79 & 100 & & \\
\hline & \begin{tabular}{|l|}
$\begin{array}{l}\text { b. Instalasi air hujan \& } \\
\text { rabat beton keliling } \\
\text { bangunan }\end{array}$ \\
\end{tabular} & 1.22 & 100 & & \\
\hline & MLAH & 100.00 & & & \\
\hline \multicolumn{3}{|c|}{ KESIMPULAN PENGAMATAN: } & \multicolumn{3}{|c|}{ TINGKAT KERUSAKAN : } \\
\hline \multirow{4}{*}{\multicolumn{2}{|c|}{$\begin{array}{l}\% \text { Tingkat Kerusakan } \\
\text { Jenis Perawatan } \\
\text { Luas Bangunan/Ruang }\end{array}$}} & $: \ldots \ldots$ & Ringan & : & $\leq 30 \%$ \\
\hline & & $: \ldots \ldots$ & Sedang & : & $>30 \%-45 \%$ \\
\hline & & $: \ldots \ldots$. & Berat & : & $>45 \%-65 \%$ \\
\hline & & & Total & : & $>65 \%$ \\
\hline
\end{tabular}

\subsection{METODE PENELITIAN}

\subsubsection{Teknik Pengambilan Data}

Pengambilan data dilakukan dengan survey lapangan, dimana peneliti mengamati kondisi tiap komponen elemen bangunan. Pengukuran luas kerusakan komponen elemen bangunan dilakukan dengan menggunakan meteran dan dihitung persentase nya sesuai dengan peraturan dari Kemendikbud (2015) yang sudah dijelaskan di Tabel 2.1. Persentase kerusakan bangunan diisi pada lembaran checklist penelitian, yang mengacu pada Tabel 2.3

\subsubsection{Teknik Pengolahan \& Analisis Data}

Teknik pengolahan data dilakukan dengan menghitung bobot persentase kerusakan tiap komponen/elemen bangunan, sesuai dengan komponen standar penilaian tingkat kerusakan bangunan pada Tabel 2.3. Setelah didapati nilai persentase kerusakan, maka tiap komponen bangunan kemudian digolongkan tingkat kerusakannya sesuai empat kategori tingkat kerusakan, yaitu :

- Rusak Ringan (RR) : $\leq 30 \%$

- Rusak Sedang (RS) : > 30\%- $45 \%$

- Rusak Berat (RB) : $>45 \%-65 \%$

- Rusak Total (RT) $: \geq 65 \%$

\section{HASIL DAN PEMBAHASAN}

Data diambil pada 100 Sekolah Menengah Pertama (SMP) yang tersebar pada 10 Kabupaten di Provinsi Maluku, sesuai Tabel 3.1.

Tabel 3.1. Daftar Jumlah Sekolah pada Kabupaten di Provinsi Maluku

\begin{tabular}{|r|l|c|} 
No & \multicolumn{1}{|c|}{ Kota/Kabupaten } & Jumlah Sekolah \\
& & \\
\hline 1 & KOTA AMBON & 8 \\
\hline 2 & KAB. MALUKU TENGAH & 20 \\
\hline 3 & KOTA TUAL & 3 \\
\hline 4 & KAB. SERAM BAGIAN BARAT (SBB) & 26 \\
\hline 5 & KAB. SERAM BAGIAN TIMUR (SBT) & 12 \\
\hline 6 & KAB. MALUKU TENGGARA & 9 \\
\hline 7 & KAB. BURU & 9 \\
\hline 8 & KAB. BURU SELATAN & 8 \\
\hline 9 & KAB. MALUKU TENGGARA BARAT (MTB) & 3 \\
\hline 10 & KAB. MALUKU BARAT DAYA (MBD) & 2 \\
\hline & TOTAL & $\mathbf{1 0 0}$ \\
\hline
\end{tabular}

Analisis tingkat kerusakan dilakukan pada dua kategori ruangan yaitu : (1) Ruang kelas dan (2) Ruang Penunjang Lainnya (RPL) yang terdiri dari: perpustakaan, laboratorium, ruang kesenian/keterampilan, UKS \& Gudang, ruang kepsek \& wakepsek, ruang guru, ruang TU/Administrasi \& ruang kurikulum, KM/WC 
Guru \& siswa, serta ruang OSIS. Analisis tersebut dilakukan dengan pertimbangan bahwa bangunan/ruang tersebut dapat mewakili blok massa bangunan pada tiap-tiap sekolah. Tabel 3.2 menunjukan contoh analisis kerusakan bangunan pada ruang perpustakaan di SMP Negeri 1 Tehoru, Kabupaten Maluku Tengah.

Tabel 3.2. Analisis Kerusakan Ruang Perpustakaan SMP Negeri 1 Tehoru Kabupaten Maluku Tengah

\begin{tabular}{|c|c|c|c|c|c|}
\hline \multirow[b]{2}{*}{ No } & \multirow[b]{2}{*}{$\begin{array}{c}\text { Komponen \& Sub } \\
\text { Komponen Bangunan }\end{array}$} & \multicolumn{2}{|c|}{ Bobot (\%) } & \multicolumn{2}{|c|}{ Tingkat Kerusakan (\%) } \\
\hline & & $\begin{array}{c}\text { Terhadap } \\
\text { seluruh } \\
\text { bangunan }\end{array}$ & $\begin{array}{l}\text { Kerusakan } \\
\text { maksimum }\end{array}$ & Bobot & Nilai \\
\hline (1) & (2) & (3) & (4) & (5) & $(6)=(3) \times(5)$ \\
\hline \multirow[t]{4}{*}{1} & Atap & & & & \\
\hline & a. Penutup Atap & $10.56 \%$ & $100.00 \%$ & $100.00 \%$ & $10.56 \%$ \\
\hline & b. Rangka Atap & $11.62 \%$ & $100.00 \%$ & $40.00 \%$ & $4.65 \%$ \\
\hline & c. Listplank \& Talang & $2.06 \%$ & $100.00 \%$ & $100.00 \%$ & $2.06 \%$ \\
\hline \multirow[t]{4}{*}{2} & Plafond & & & & \\
\hline & a. Rangka Plafond & $4.67 \%$ & $100.00 \%$ & $100.00 \%$ & $4.67 \%$ \\
\hline & b. Penutup \& List & $5.06 \%$ & $100.00 \%$ & $100.00 \%$ & $5.06 \%$ \\
\hline & c. Cat Plafond & $1.41 \%$ & $100.00 \%$ & $100.00 \%$ & $1.41 \%$ \\
\hline \multirow[t]{4}{*}{3} & Dinding & & & & \\
\hline & a. Kolom \& Ring balk & $9.66 \%$ & $100.00 \%$ & $0.00 \%$ & $0.00 \%$ \\
\hline & $\begin{array}{l}\text { b. Pas. Bata \& Dinding } \\
\text { Pengisi }\end{array}$ & $13.68 \%$ & $100.00 \%$ & $0.00 \%$ & $0.00 \%$ \\
\hline & c. Cat Dinding & $1.65 \%$ & $100.00 \%$ & $0.00 \%$ & $0.00 \%$ \\
\hline \multirow[t]{4}{*}{4} & Kusen, Pintu \& Jendela & & & & \\
\hline & a. Kusen & $2.70 \%$ & $100.00 \%$ & $0.00 \%$ & $0.00 \%$ \\
\hline & b. Daun Pintu & $2.47 \%$ & $100.00 \%$ & $0.00 \%$ & $0.00 \%$ \\
\hline & c. Daun Jendela & $5.15 \%$ & $100.00 \%$ & $15.00 \%$ & $0.77 \%$ \\
\hline \multirow[t]{3}{*}{5} & Lantai & & & & \\
\hline & a. Struktur bawah & $2.89 \%$ & $100.00 \%$ & $0.00 \%$ & $0.00 \%$ \\
\hline & b. Penutup Lantai & $8.96 \%$ & $100.00 \%$ & $100.00 \%$ & $8.96 \%$ \\
\hline \multirow[t]{3}{*}{6} & Pondasi & & & & \\
\hline & a. Pondasi & $11.15 \%$ & $100.00 \%$ & $0.00 \%$ & $0.00 \%$ \\
\hline & b. Sloof & $3.30 \%$ & $100.00 \%$ & $0.00 \%$ & $0.00 \%$ \\
\hline \multirow[t]{3}{*}{7} & Utilitas & & & & \\
\hline & a. Listrik & $1.79 \%$ & $100.00 \%$ & $100.00 \%$ & $1.79 \%$ \\
\hline & $\begin{array}{l}\text { b. Instalasi air hujan \& } \\
\text { rabat beton keliling }\end{array}$ & $1.22 \%$ & $100.00 \%$ & $60.00 \%$ & $0.73 \%$ \\
\hline & JUMLAH & $100.00 \%$ & & & $40.66 \%$ \\
\hline
\end{tabular}

Total persentase menunjukan nilai sebesar $40,66 \%$ yang berarti bangunan perpustakaan pada SMP Negeri 1 Tehoru masuk dalam kategori Rusak Sedang (RS).

Data hasil analisis tingkat kerusakan pada tiap kabupaten kemudian digabungkan dalam rekapitulasi penilaian tingkat kerusakan bangunan gedung SMP dan diperoleh 798 ruang kelas, dimana 143 ruang kelas dalam kondisi baik, 554 ruang kelas dalam kondisi Rusak Ringan (RR), 57 ruang kelas dalam kondisi Rusak Sedang (RS), 28 ruang kelas dalam kondisi Rusak Berat (RB) dan 16 ruang kelas dalam kondisi Rusak Total (RT). Persentase tingkat kerusakan ruang kelas dapat dilihat pada Gambar 4.1.
Gambar 4.1. Grafik Persentase Tingkat Kerusakan Ruang Kelas SMP di provinsi Maluku

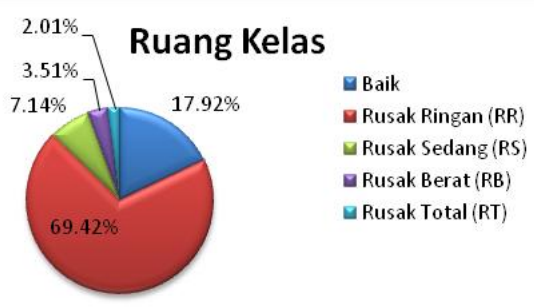

Kemudian, dari 799 ruang penunjang lainnya (RPL) yaitu perpustakaan, laboratorium, ruang kesenian/keterampilan, UKS \& Gudang, ruang kepsek \& wakepsek, ruang guru, ruang TU/Administrasi \& ruang kurikulum, KM/WC Guru \& siswa, serta ruang OSIS, didapati bahwa 277 RPL dalam kondisi baik, 378 RPL dalam kondisi Rusak Ringan (RR), 59 RPL dalam kondisi Rusak Sedang (RS), 45 RPL dalam kondisi Rusak Berat (RB), dan 40 RPL dalam kondisi Rusak Total (RT). Persentase tingkat kerusakan ruang penunjang lainnya (RPL) dapat dilihat pada Gambar 4.2.

Gambar 4.2. Grafik Persentase Tingkat Kerusakan Ruang Penunjang Lainnya (RPL) SMP di provinsi Maluku

$\begin{aligned} & \text { Ruang Penunjang Lainnya } \\ & \\ & \square \text { Baik } \\ & \quad \square \text { Rusak Ringan (RR) } \\ & \square \text { Rusak Sedang (RS) } \\ & \square \text { Rusak Berat (RB) } \\ & \square \text { Rusak Total (RT) }\end{aligned}$

\section{KESIMPULAN \& SARAN}

\subsection{KESIMPULAN}

Dari hasil analisis data pada 100 sekolah menengah pertama (SMP) di 10 kabupaten di Provinsi Maluku, didapati 798 ruang kelas dan 799 ruang penunjang lainnya berupa perpustakaan, laboratorium, ruang kesenian/keterampilan, UKS \& Gudang, ruang kepsek \& wakepsek, ruang guru, ruang TU/Administrasi \& ruang kurikulum, KM/WC Guru \& siswa, serta ruang OSIS. Dari hasil input data prasarana bangunan gedung SMP kemudian diranking berdasarkan tingkat kerusakannya yaitu :

1. Ruang kelas dalam keadaan baik sebanyak $17.92 \%$, rusak ringan (RR) sebanyak $69.42 \%$, rusak sedang (RS) sebanyak $7.14 \%$, rusak 
berat (RB) sebanyak $3.51 \%$, dan rusak total (RT) sebanyak $2.01 \%$.

2. Ruang penunjang lainnya (perpustakaan, laboratorium, ruang kesenian/keterampilan, UKS \& Gudang, ruang kepsek \& wakepsek, ruang guru, ruang TU/Administrasi \& ruang kurikulum, KM/WC Guru \& siswa, serta ruang OSIS) dalam keadaan baik sebanyak $34.67 \%$, rusak ringan (RR) sebanyak $47.31 \%$, rusak sedang (RS) sebanyak 7.38\%, rusak berat (RB) sebanyak 5.63\%, dan rusak total (RT) sebanyak $5.01 \%$.

\subsection{SARAN}

Berdasarkan kesimpulan diatas, maka dapat diberikan saran berupa rekomendasi ke pemerintah daerah yakni :

1. Kerusakan bangunan dengan persentase terbesar ada pada ruang kelas dengan kategori rusak ringan (RR) sebesar $69.42 \%$. Prioritas kebijakan untuk alokasi dana renovasi gedung SMP agar ditujukan untuk renovasi ruang kelas, mengingat proses belajar mengajar utama dilakukan di dalam ruang kelas.

2. Kerusakan bangunan gedung yang masuk kategori rusak berat (RB) dan rusak total (RT) pada ruangan kelas dan ruang penunjang lainnya, agar diprioritaskan utama untuk dilakukan rehabilitasi, karena bersifat mendesak (urgent) sehingga dapat membantu mengembalikan proses belajar mengajar di sekolah.

3. Pemerintah daerah perlu melakukan pelatihan (diklat) tentang manajemen perawatan bangunan gedung sekolah sehingga dapat mengurangi resiko tingkat kerusakan bangunan yang semakin besar.

\section{DAFTAR PUSTAKA}

Dardiri, A. 2012. Analisis Pola, Jenis dan Penyebab Kerusakan Bangunan Gedung Sekolah Dasar. Jurnal Teknologi dan Kejuruan Vol 35 No.1, Februari 2012 p.2180.

Dirjen Cipta Karya, Departemen PU. 2008. Peraturan Menteri Pekerjaan Umum No. 24/PRT/M/2008 tanggal 30 Desember 2008 tentang Pedoman Pemeliharaan dan Perawatan Bangunan Gedung.

Dirjen Cipta Karya, Departemen PU. 2006. Pedoman Teknis Rumah dan Bangunan Gedung Tahan Gempa.

Iriana, R dan Riana A. 2012. Analisa Tingkat Kerusakan dan Estimasi Biaya Perbaikan Bangunan Gedung Sekolah (Studi Kasus SDN 006 Jalan Cempedak, SDN 021/022 Jalan Mujair Raya dan SDN 013 Jalan Bambu Kuning Pekanbaru). Jurnal Teknik Sipil November 2012 Universitas Riau. p1.

Kemdikbud. 2017. Ikhtisar Data Pendidikan Tahun 2016/2017. Sekjen Pusat Data dan Statistik Pendidikan dan Kebudayaan. Jakarta.

Kemdikbud RI, Direktorat Pembinaan Sekolah Dasar 2015. Panduan Verifikasi Bantuan Revitalisasi Sekolah Dasar. Jakarta.

Parmo, Moh. Hadi Sucipto \& Sumarkan. 2016. Penilaian Kondisi Bangunan Gedung Sekolah Dasar Negeri. Studi Kasus di Sekolah Dasar Negeri se-Kabupaten Madiun. EMARA Indonesian Journal of Architecture Vol. 2 No. 1, Agustus 2016, ISSN 24607878, e-ISSN 2477-5975 